\title{
Mobile intracardiac calcinosis: a new risk of thromboembolism in patients with haemodialysed end stage renal disease
}

\author{
K Tsuchihashi, A Nozawa, S Marusaki, N Moniwa, Y Oh-numa, A Kuno, S Takagi, \\ H Takizawa, N Ura, K Shimamoto
}

\begin{abstract}
Cardiac calcinosis is a common complication of end stage renal disease. A newly observed risk of thromboembolism is reported in four patients with mobile cardiac calcinosis, treated with long term dialysis. Rapidly growing mobile calcification was confirmed by echocardiography. Each patient had an imbalance in serum calcium $\times$ inorganic phosphate $(\mathbf{C a} \times \mathbf{P}$ product $\geqslant 50$ ); this imbalance could not be treated due to the sudden death of the patient or the need for surgical resection to prevent recurrent cerebral thromboembolism. Histological examination revealed intracardiac calcinosis in three cases, and each case showed haemodialysis hypoparathyroidism (intact PTH $<160 \mathrm{pg} / \mathrm{ml}$ ). Thromboembolism in such cases is rare, however it indicates a need for cautious echocardiographic monitoring in end stage renal disease in patients with an uncontrolled $\mathbf{C a} \times \mathbf{P}$ product.

(Heart 1999;82:638-640)
\end{abstract}

Keywords: cardiac mass; intracardiac mobile calcinosis; haemodialysis hypoparathyroidism; thromboembolism; end stage renal disease

Abnormal calcification of the cardiovascular system-for example, mitral annular calcinosis, calcified aortic root, and arterial calcification, is a well known complication of end stage renal disease treated with long term haemodialysis, and such complications often result in fatal cardiac complications such as valvar heart disease, ${ }^{12}$ congestive heart failure, ${ }^{3}$ and obstructive and atherosclerotic arterial disease. ${ }^{45}$ The serum calcium $\times$ inorganic phosphate product $(\mathrm{Ca} \times \mathrm{P}$ product $)$ is thought to have a partial effect on systemic, but not cardiac, calcinosis in patients treated with haemodialysis using high performance membrane which controls for serum calcium inorganic phosphate levels. ${ }^{6}$ Furthermore, little consideration has been given to the possibility of thromboembolism of intracardiac calcified deposits in end stage renal disease.

This paper discusses four cases of rare mobile pseudocardiac tumours, which were histologically proved to be intracardiac calcinosis, and is the first report of intracardiac mobile calcinosis with thromboembolism in haemodialysed end stage renal disease patients.

\section{Case 1}

A 70 year old woman with interstitial nephritis due to recurrent pyelonephritis had been treated with dialysis since 1991. Since 1995, she had effort angina and was admitted in early 1997 for examination of this condition. Stress myocardial scintigraphy revealed reversible ischaemia in the anteroseptal and inferior region, and antianginal drugs, including $\beta$ blockade, enabled her to reach an exercise capacity of 5.0 METs. Haemodialysis was performed with bicarbonate dialysate three times a week.

In February 1998, the patient was again admitted for echocardiography, which showed a crotchet shaped mobile interventricular mass (fig 1). Laboratory examination revealed renal anaemia with haemoglobin $73 \mathrm{~g} / 1$. Serum calcium $\times$ inorganic phosphate product $(\mathrm{Ca}$ $(2.6 \mathrm{nmol} / 1 \quad(10.5 \mathrm{mg} / \mathrm{dl})) \times \mathrm{P} \quad(2.3 \mathrm{nmol} / 1$ $(7.0 \mathrm{mg} / \mathrm{dl})))$ was 73.6 . Serum parathyroid hormone (intact PTH) was $16.9 \mathrm{pg} / \mathrm{ml}$, magnesium was $0.7 \mathrm{nmol} / 1$, vitamin $\mathrm{D}$ was $26 \mathrm{nmol} / \mathrm{l}$, and aluminum was $593 \mathrm{nmol} / \mathrm{l}$. After treatment with a supplement of $\mathrm{CaCO}_{3}$ (3.0 g daily) and active vitamin $\mathrm{D}_{3}$ (alfacalidol $0.25 \mu \mathrm{g}$ daily), $\mathrm{Ca} \times \mathrm{P}$ product dropped to 48.4. However, renal anaemia worsened, and the patient developed angina at night with dyspnoea. In June 1998, she felt orthopnoea at night, which could not be relieved with intravenous glycerol trinitrate. She died four hours later from cardiogenic shock.

Necropsy revealed a white steak-like mass attached to the membranous portion of the interventricular septum. Microscopic evaluation showed typical tumoral calcinosis and continuous calcification of the mitral annulus and the aortic root, which was partially connected to interventricular septum where the tumour was attached. Fresh massive myocardial infarction was also confirmed, with triple vessel disease.

\section{Case 2}

A 66 year old woman with renal failure due to renal tuberculosis after nephrectomy had been 


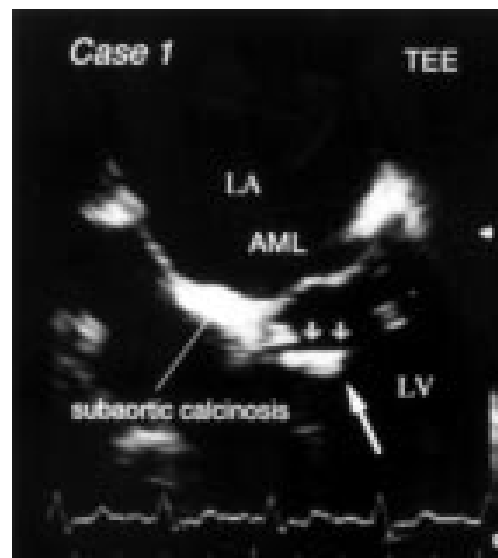

64 yrs female (SMU)

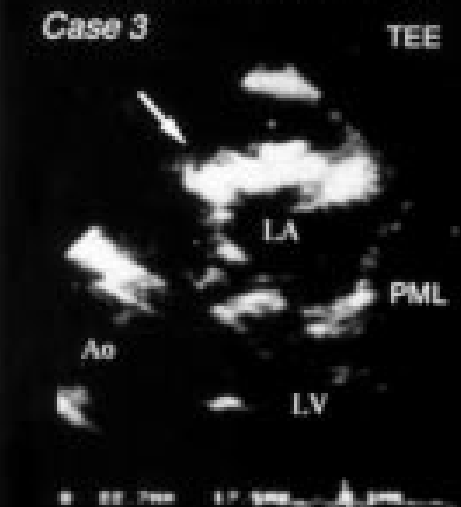

55 yrs. female(OKH)
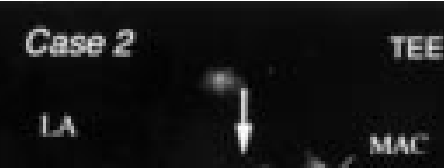

$\mathrm{MAC}$

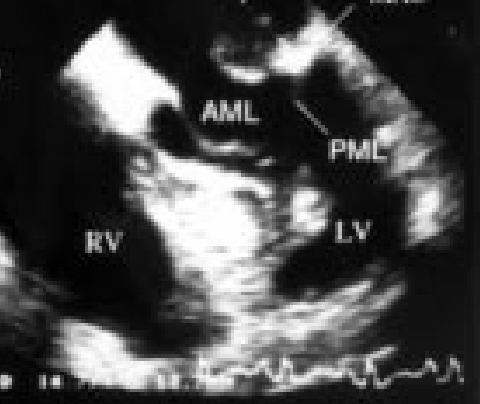

66 yrs female (HPK)

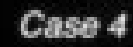

TEE

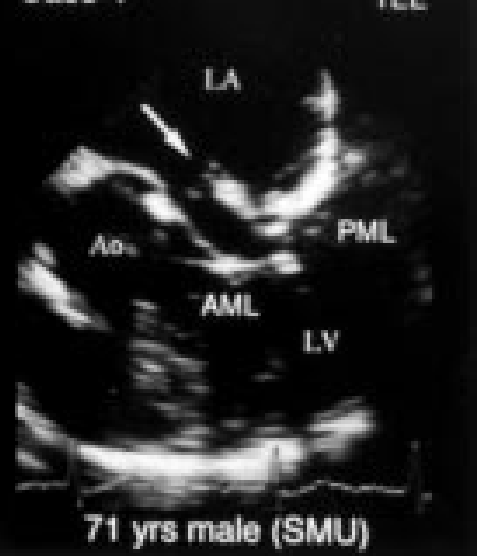

Figure 1 Case 1: transoesophageal echocardiography (TEE) showing a mobile intracardiac tumour $(6 \times 14 \mathrm{~mm})$ with homogeneous hyperechoic characteristics, attached to the membranous portion of interventricular septum with tumour. Case 2:

echocardiography after cerebral thromboembolism, showing a heterogenic high echoic mobile intracardiac tumour at the base of the posterior mitral leaflet (PML), and the rapid growth of the tumour $(14.7 \times 13.7 \mathrm{~mm})$. Case 3: echocardiography showing rapidly growing intracardiac mass $(14 \times 12 \mathrm{~mm})$ on posterior wall of left atrium (LA; mid-panel). Case 4 : transoesophageal echocardiography showing a homogeneous high echoic mobile intra-atrial tumour located in anterior mitral valve $(A M V)(8 \times 12 \mathrm{~mm})$. AML, anterior mitral leaflet; Ao, aorta; LV, left ventricle; $M A C$, mitral annular calcinosis; RV, right ventricle.

treated with haemodialysis for three years. In May 1998, echocardiography revealed a giant mobile left atrial mass attached to the base of the posterior mitral leaflet. Four days later she suddenly had total right hemiplegia. In June, she was admitted for further evaluation of the left atrial tumour which had increased in size; surgical resection was proposed to prevent recurrent thromboembolism. The patient also had renal anaemia with haemoglobin $105 \mathrm{~g} / 1$; the $\mathrm{Ca}$ $(3.7 \mathrm{nmol} / 1 \quad(14.8 \mathrm{mg} / \mathrm{dl})) \times \mathrm{P} \quad(1.4 \mathrm{nmol} / 1$ $(4.3 \mathrm{mg} / \mathrm{dl}))$ product was 61.1 , and intact PTH was strictly suppressed to insensitivity level $(<2.0 \mathrm{pg} / \mathrm{ml})$. Intraoperative findings showed a white steak-like mass attached to the mitral leaflet with superficial red thrombus. Microscopic examination also showed typical massive calcinosis with fibrous sequestration and thrombi formation.

\section{Case 3}

A 55 year old woman with diabetic nephropathy had been treated with continuous ambulatory peritoneal dialysis for four years. Echocardiography (fig 1) in late 1996 revealed a mobile left atrial mass attached to the base of the posterior left atrial wall, and she was admitted for further evaluation. Due to the rapid growth of the mass, we recommended surgical resection, but the patient rejected this suggestion. The patient also had renal anaemia with haemoglobin $53 \mathrm{~g} / \mathrm{l}$, and the $\mathrm{Ca}$ $(2.7 \mathrm{nmol} / 1 \quad(11.0 \mathrm{mg} / \mathrm{dl})) \times \mathrm{P} \quad(1.6 \mathrm{nmol} / 1$ $(5.1 \mathrm{mg} / \mathrm{dl}))$ product was 56.1 ; her intact PTH level was $17.1 \mathrm{pg} / \mathrm{ml}$. Four months later she died suddenly. Necropsy revealed destruction of the intra-atrial mass, which had been attached to the posterior left atrial wall, and embolism in the cerebrovascular system.

\section{Case 4}

A 71 year old man with chronic glomerulonephritis had been haemodialysed for eight years. One year before admission, he had felt dyspnoea on effort. When atrial fibrillation became his dominant rhythm, his exercise was limited to New York Heart Association (NYHA) functional class III. He had been taking calcium bicarbonate $3.0 \mathrm{~g}$ and active vitamin $D_{3} 0.50 \mu \mathrm{g}$ daily for eight years.

The patient was admitted in June 1998. Echocardiography revealed noticeable mitral annular calcinosis with left atria mobile tumours attached to the base of the anterior mitral leaflet; $1.1 \mathrm{~cm}^{2}$ of functional mitral stenosis was also detected in the Gorlin mitral valve area. The $\mathrm{Ca}(2.9 \mathrm{nmol} / \mathrm{l}) \times \mathrm{P}(1.7 \mathrm{nmol} /$ 1) product was 62.0; the patient's intact $\mathrm{PTH}$ was severely depressed at $9.0 \mathrm{pg} / \mathrm{ml}$. Magnesium, vitamin $\mathrm{D}$, and aluminum levels were all within normal range. ${ }^{99 \mathrm{~m}}$ Technetium MDP bone scintigraphy revealed intracardiac calcinosis, and surgical resection and mitral valve replacement were performed for symptomatic mitral valve stenosis and to prevent recurrent thromboembolism.

\section{Discussion}

We report four cases of mobile cardiac calcinosis accompanied by mitral annular and subaortic calcification; this is also the first report of cardiac tumoural calcinosis as a cause of thromboembolism in end stage renal disease. These cases illustrate a very rare complication, which is important in patient prognosis in end stage renal disease.

It is not usual to perform frequent echocardiographic evaluation in end stage renal disease. We cannot comment on the precise incidence of intracardiac tumoral calcinosis in our study, but we speculate that the incidence of mobile calcinosis is not high, as the echocardiographic database on end stage renal disease in our three hospitals has only 300 cases. Detection of mitral annular calcinosis and calcification of the aortic root by echocardiography is not difficult, but annular calcinosis can mimic an intracardiac mass. In our cases, early detection of mobile calcinosis had failed even with an interval of 6-12 months between evaluations. A further difficulty with diagnosis is how to differentiate mobile calcinosis from primary cardiac tumours or intracardiac thrombi; dense continuity from the mitral or calcified aortic root and homogeneous high echoic characteristics can be helpful in such cases. 
Systemic massive calcinosis on extraskeletal tissue is not a rare complication of end stage renal disease, especially in patients treated with long term haemodialysis ${ }^{6}$; cardiac calcinosis, like mitral annular calcinosis and subaortic calcification, is also common. However, it is not clearly understood why the cardiac base is vulnerable to calcium deposits. In extraskeletal calcinosis, $\mathrm{Ca}-\mathrm{P}$ deposits on the multifollicular fibrous wall are also seen frequently in the hyperkinetic joint capsule. The similarity of the histological and pathophysiological background of the target tissue may explain the deposit of fibrous tissue in the cardiac base. But the clinical significance of cardiac calcinosis is very different from joint calcinosis because the rapid progression of cardiac calcinosis is due to exposure to the bloodstream, ${ }^{7}$ which could produce a secondary thrombus formation. Furthermore, tissue resistance, which might limit the growth of the tumour, is very low and speed of growth in cardiac tissue could be too high. Finally, the early detection of cardiac calcinosis is more difficult than the detection of joint calcinosis.

Secondary hyperparathyroidism plays a key role in the cause of cardiac calcification, and a serum marker may be an increased level of inorganic phosphate and serum calcium, where the $\mathrm{Ca} \times \mathrm{P}$ product is $<50{ }^{8}$ Serum magnesium, vitamin $\mathrm{D}$, and serum aluminum are all influential factors. In our cases, only the $\mathrm{Ca} \times \mathrm{P}$ product was high. Modification of treatment through the use of low calcium dialysate, high performance membrane, ${ }^{9}$ and a drug such as vinposetin ${ }^{10}$ on the $\mathrm{Ca} \times \mathrm{P}$ product, gave some beneficial effects for systemic tumoral calcinosis, but not for cardiac calcinosis.

A further symptom of rapid cardiac calcinosis is hypoparathyroidism. Recently, Akizawa et al reported that patients on haemodialysis with hypoparathyroidism had a higher incidence of metastatic calcification, ${ }^{11}$ which resulted from the decreased reservoir function of bone for absorbed calcium and phosphate from the intestine. ${ }^{12}$ Moreover, generally administered calcium and active vitamin $\mathrm{D}_{3}$ could exacerbate hypercalcaemia, and might increase the risk of tumoral calcinosis in the cardiovascular system of patients with end stage renal disease and hypoparathyroidism. Patients with hypopara- thyroidism are defined as having intact PTH $<160 \mathrm{pg} / \mathrm{ml}$. Thus, all of our cases may have had dialysis related hypoparathyroidism, which could have contributed to the development of cardiac calcinosis, rather than the calcinosis being a result of a $\mathrm{Ca} \times \mathrm{P}$ product of $<50$.

Nevertheless, it seems that anticoagulation treatment is essential for the prevention of secondary formed thrombi. Additionally, surgical resection should be considered to be a primary treatment, as mobile tumoral calcinosis in the cardiovascular system carries a high risk of thromboembolism of cardiac origin.

In conclusion, cardiac mobile tumoral calcinosis, a rare complication of end stage renal disease, carries a high risk of thromboembolism, especially when the patient has poorly controlled serum $\mathrm{Ca} \times \mathrm{P}$ product and haemodialysed hypoparathyroidism. A cautious echocardiographic evaluation could also be useful in the detection of mobile cardiac tumoral calcinosis.

1 Dashkoff N, Karacuschansky M, Come PC, et al. Echocardiographic features of mitral annulus calcification. Am diographic features of

2 Nair CK, Aronow WS, Sketch NH, et al. Clinical and echocardiographic characteristics of patients with mitral annulus calcification. Am f Cardiol 1983;51:1992-6.

3 Rostand SG, Sanders C, Kirk SG, et al. Myocardial calcification and cardiac dysfunction in chronic heart failure. $\mathrm{Am}$ 7 Med 1988;85:651-7.

4 Kudoh Y, Iimura O. Study on the atherosclerosis mechanism in chronic haemodialysis. Fpn Circ F 1987;51:63141.

5 Nagao K, Tsuchihashi K, Ura N, et al. Appropriate hematocrit levels of erythropoietin supplemental therapy in endstaged renal failure complicated by coronary artery disease. Can $\mathcal{F}$ Cardiol 1997;13:747-53.

6 Hampers CL, Katz AI, Wilson RE, et al. Calcium metabolism and osteodystrophy after renal transplantation. Arch Intern Med 1969;124:282-91.

7 DePace NL, Rohrer AH, Kotler MN, et al. Rapidly progressing, massive mitral annular calcification. Occurprogressing, massive mitral annular calcification. Occurrence in a patient with
Med $1981 ; 141: 1663-70$.

8 Katz AI, Hampers CL, Merrill JP. Secondary hyperparathyroidism and renal osteodystrophy in chronic renal failure. Analysis of 195 patients, with observations of chronic dialysis, kidney transplantation, and subtotal parathyroidectomy. Medicine 1969;48:337-74

9 Fernandez E, Montoliu J. Successful treatment of massive uremic tumoral calcinosis with daily haemodialysis and very low calcium dialysate [letter]. Nephrol Dial Transplant 1994;9:1207-9.

10 Ueyoshi A, Ota K. Clinical appraisal of vinpocetine for the removal of intractable tumoral calcinosis in haemodialysis patients with renal failure. F Int Med Res 1992;20:435-43. characteristics of hypoparathyroidism in dialysis patients. Kidney Int 1997;52:S72-4.

12 Kurz P, Monier-Faugere MC, Bognar B, et al. Evidence for abnormal calcium homeostasis in patients with adynamic bone disease. Kidney Int 1994;46:855-61. 